\title{
Study of Thermal Comfort in a Room with Windows at Adjacent Walls along with Additional Vents
}

\author{
D. Prakash ${ }^{1 *}$ and P. Ravikumar ${ }^{2}$ \\ 'Associate Professor, Arasu Engineering College, Kumbakonam, India; dee_prakas@yahoo.com \\ 2Professor, St. Joseph College of Engineering and Technology, Thanjavur, India; \\ paramasivamravikumar@yahoo.co.in
}

\begin{abstract}
Thermal comfort has become a problem to the occupants of many residential building without air-conditioning system in hot climates. Natural ventilation is the only positive option for those residential buildings to improve their thermal comfort. Hence, present work is focused in analyzing the indoor characteristics of air and thermal comfort prevailed inside the room with windows at their adjacent walls along with the additional vents. Additional openings include a roof vent and a vent in the windward side wall. In this study, Computational Fluid Dynamic technique is employed to study the indoor airflow behavior and the CFD simulation was validated with the network model. 3-Dimensional model was created and $k-\varepsilon$ turbulence model was used. Indoor airflow behavior was studied under various locations of the roof vent and best location was identified. Also another additional vent in the windward side wall was provided and analyzed under various shapes like cylindrical and nozzle shape. Air velocity, temperature, low temperature zone, low velocity zone and Predicted mean vote contours are predicted for all the simulated cases. These results are very much useful to study the effectiveness of the additional vent. Finally, the best location for the roof vent and the best shape for additional vent at windward side wall were identified.
\end{abstract}

Keywords: Ventilation, Thermal Comfort, Residential Building, CFD, PMV.

\section{Introduction}

Thermal comfort is the state of mind that expresses satisfaction to the thermal environment. It determines whether or not an indoor environment is satisfactory to the occupant. Thermal comfort is important for the well-being and productivity of occupants. It can be defined in terms of a range of environmental and physiological factors which include air velocity and temperature, turbulence intensity, mean radiant temperature, vector radiant temperature, humidity, clothing level, metabolic rate and external activity level. Providing good ventilation is one way to improve the indoor thermal comfort.

Ventilation is the process by which clean air is intentionally provided to the space from the outdoor and the stale air is removed. The entrapped air is either mixed with the air which is already present in the space for dilution (or) used to displace the air in the space. Good ventilation improves the health and productivity of occupants. Poor ventilation increases bacteriological concentration. The required quantity of ventilation depends on the amount and nature of pollutants present in the space. Ventilation can be enhanced either by natural or mechanical means.

Now a days, the demand for the energy encourages natural ventilation in the buildings. Mendell et al. [13] reports that, some significant symptoms are being caused by mechanical ventilation for the occupants. Fisk et al. [9] states that, if natural ventilation itself improves indoor environmental condition, and then it is preferable to improve worker's productivity. Creation of good natural ventilation provides comfortable living and working conditions without consumption of energy. However, the main draw back

*Corresponding author:

D.Prakash (dee_prakas@yahoo.com) 
in natural ventilation is lack of control, in which unreliable driving forces can result in periods of inadequate ventilation, followed by periods of over ventilation and excessive energy waste. Good design can provide some control to the flow of air. In this contest present work is focused to improve the thermal comfort by providing additional vents in the room with windows at their adjacent walls. The choice of room with windows at their adjacent walls for investigation was discussed [15]. Most of the literature includes the study of indoor air flow characteristics in room with single sided window $[17,12,8]$ and windows at their opposite walls $[16,1,4,5]$.

The study on indoor airflow has traditionally performed by experimental and empirical model and most study was limited to very simplified models of the physical indoor environment, due to the complicated flow characteristics of practical ventilation flows. CFD opened a new era to numerically predict the indoor climate on a detailed level with high flexibility in terms of configurations and boundary conditions.

A major advantage of CFD is that it has the potential to provide detailed flow patterns and temperature distributions throughout the space, and the calculations can, in principle, include all the likely physical processes such as heat transfer from surfaces and transient behavior. CFD can also, in principle, deal with the complex geometry of a space and the arrangement and distribution of heat sources. With the aid of CFD, Hoang et al. [10], Huo et al. [11], Rouaud et al. [14], Song et al. [6] performed the air flow analysis in the buildings.

With all these information, present work includes CFD technique to study the internal air flow characteristics and indoor thermal comfort in a room with additional vents.

\section{Test Case and CFD Methodology}

The schematic arrangement of the test case room with windows at their adjacent wall and its CFD model with the atmospheric zone are shown in Figure 1. Two different cases are analyzed in this study: room with roof vent and room with additional vent in the windward side wall. In the first case, single vent of square shape was provided in the roof at various locations and its effectiveness on ventilation and thermal comfort was studied. From the first study, the best location for roof vent is identified. In the second case additional vent at windward side wall was provided along with roof vent at best location. Different shapes of second vent was analyzed which includes cylindrical, convergent, divergent and convergent divergent.

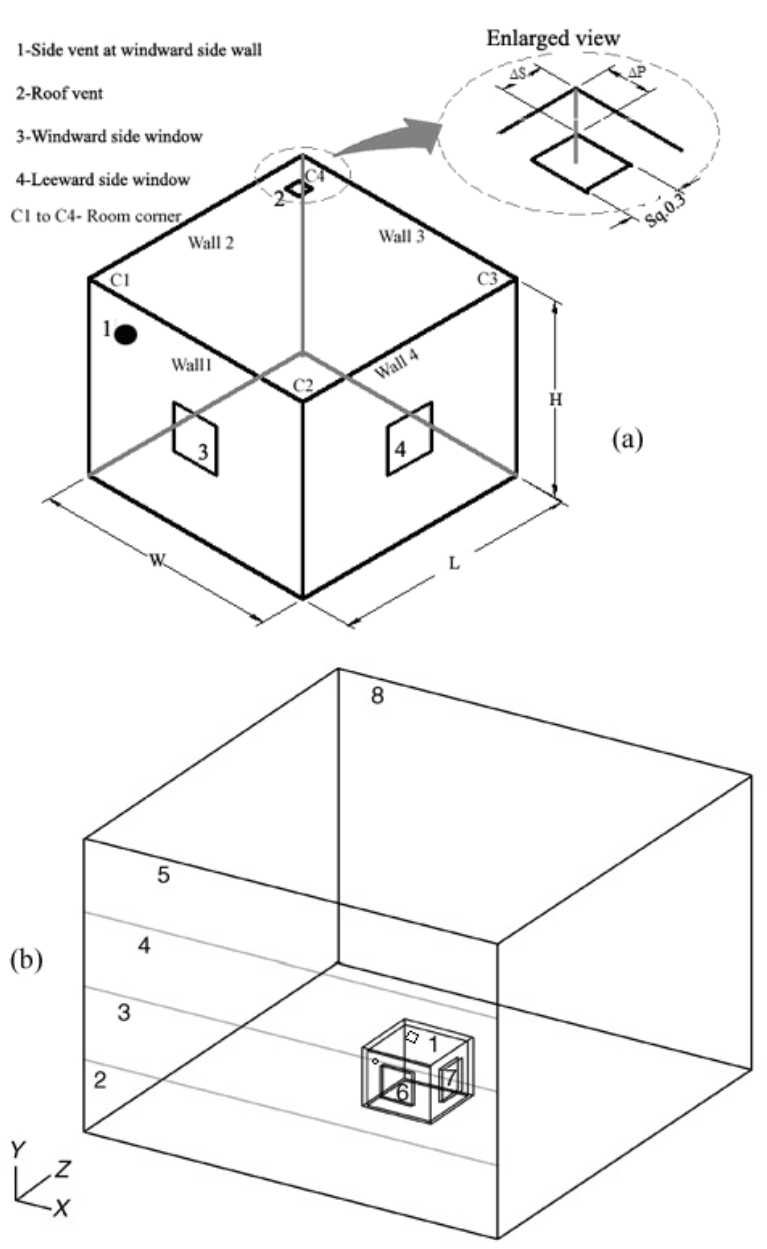

Figure 1. (a) Test case room. (b). CFD model of test case room.

The test room under investigation is of size $5 \mathrm{~m} \times 5 \mathrm{~m}$ $\mathrm{x} 4 \mathrm{~m}$. It is having two window of size $1 \mathrm{~m} \mathrm{x1} \mathrm{m}$, located at the adjacent sides of the wall as shown in Figure 1. A 3-dimensional model was created in the GAMBIT software and is shown in Figure 2.The room model was placed inside a rectangular box of size $30 \times 30 \times 20 \mathrm{~m}$ which is considered as an atmosphere.

The major assumptions involved in this analysis are as follows:

i. Ventilation due to wind force is only considered

ii. An isolated room is analyzed

iii. Air properties are assumed as a constant value with reference to atmospheric temperature

iv. Air is entering perpendicular to the window open

v. Fluctuation of wind velocity is neglected and is assumed to be constant 
Based on these assumptions, the governing equations used to be solved are as follows:

Continuity equation:

$$
\frac{\partial \rho}{\partial t}+\frac{\partial\left(\rho v_{x}\right)}{\partial x}+\frac{\partial\left(\rho v_{y}\right)}{\partial y}+\frac{\partial\left(\rho v_{z}\right)}{\partial z}=0
$$

Momentum equation:

$$
\begin{aligned}
& \frac{\partial \rho v_{x}}{\partial t}+\frac{\partial\left(\rho v_{x} v_{x}\right)}{\partial x}+\frac{\partial\left(\rho v_{x} v_{y}\right)}{\partial y}+\frac{\partial\left(\rho v_{x} v_{z}\right)}{\partial z}=\rho g_{x}-\frac{\partial P}{\partial x}+ \\
& R_{x}+\frac{\partial}{\partial x}\left(\mu_{e} \frac{\partial v_{x}}{\partial v_{x}}\right)+\frac{\partial}{\partial y}\left(\mu_{e} \frac{\partial v_{x}}{\partial y}\right)+\frac{\partial}{\partial z}\left(\mu_{e} \frac{\partial v_{x}}{\partial z}\right)+\tau_{x}
\end{aligned}
$$

$$
\begin{aligned}
& \frac{\partial \rho v_{y}}{\partial t}+\frac{\partial\left(\rho v_{x} v_{y}\right)}{\partial x}+\frac{\partial\left(\rho v_{y} v_{y}\right)}{\partial y}+\frac{\partial\left(\rho v_{y} v_{z}\right)}{\partial z}=\rho g_{y}-\frac{\partial P}{\partial y}+ \\
& R_{y}+\frac{\partial}{\partial x}\left(\mu_{e} \frac{\partial v_{y}}{\partial v_{x}}\right)+\frac{\partial}{\partial y}\left(\mu_{e} \frac{\partial v_{y}}{\partial y}\right)+\frac{\partial}{\partial z}\left(\mu_{e} \frac{\partial v_{y}}{\partial z}\right)+\tau_{y}
\end{aligned}
$$

$$
\begin{aligned}
& \frac{\partial \rho v_{z}}{\partial t}+\frac{\partial\left(\rho v_{x} v_{z}\right)}{\partial x}+\frac{\partial\left(\rho v_{y} v_{z}\right)}{\partial y}+\frac{\partial\left(\rho v_{z} v_{z}\right)}{\partial z}=\rho g_{y}-\frac{\partial P}{\partial y}+R \\
& y+\frac{\partial}{\partial x}\left(\mu_{e} \frac{\partial v_{z}}{\partial v_{x}}\right)+\frac{\partial}{\partial y}\left(\mu_{e} \frac{\partial v_{z}}{\partial y}\right)+\frac{\partial}{\partial z}\left(\mu_{e} \frac{\partial v_{z}}{\partial z}\right)+\tau_{z}
\end{aligned}
$$

where, $v_{x}, v_{y}$ and $v_{z}$ are the components of velocity in $x, y$ and $z$ directions, $\rho$ is the density, $t$ is the time, $g$ is the gravity, $\mu_{e}$ is the effective viscosity, $P$ is the pressure, $R_{i}$ is the distributed resistance, suffix $i$ is $x, y$ and $z, \tau$ is the viscous loss.

Energy Equation:

$$
\begin{aligned}
& \frac{\partial}{\partial t}\left(\rho C_{p} T_{o}\right)+\frac{\partial}{\partial x}\left(\rho v_{x} C_{p} T_{o}\right)+\frac{\partial}{\partial y}\left(\rho v_{y} C_{p} T_{o}\right) \\
& +\frac{\partial}{\partial z}\left(\rho v_{z} C_{p} T_{o}\right)=\frac{\partial}{\partial x}\left(K \frac{\partial T_{o}}{\partial x}\right)+\frac{\partial}{\partial y}\left(K \frac{\partial T_{o}}{\partial y}\right) \\
& +\frac{\partial}{\partial z}\left(K \frac{\partial T_{o}}{\partial z}\right)+W^{v}+E_{k}+Q_{v}+\phi+\frac{\partial P}{\partial t}
\end{aligned}
$$

where, $C_{p}$ is the specific heat, $T_{o}$ is the total temperature, $K$ is the thermal conductivity, $W^{v}$ is the viscous work term, $Q_{v}$ is the volumetric heat source, $\phi$ is the viscous heat generation term and $E_{k}$ is the kinetic energy.

\section{Boundary Conditions and Validation of CFD Simulation}

In general, velocity of air flow varies with respect to building height. This variation is specified either by logarithmic profile [7] or by dividing the velocity inlet into may sub inlet zones [2]. In this paper, the wind entering zone is divided in to 4 sub zones. The wind velocity at these sub zones are predicted from the equation 6 [2].

$$
V=V_{r} c H^{a}
$$

where, $V$ is the wind speed at ground level. $(\mathrm{m} / \mathrm{s}), V_{r}$ is the reference wind speed measured experimentally, $H$ is the height of the building, $c$ is the parameter relating wind speed to terrain nature ( 0.68 in the open country terrain), and a is the exponent relating wind speed to the height above the ground ( 0.17 in the open county terrain). Ambient temperature is specified as $306 \mathrm{~K}$. Free slip boundary conditions are employed to the wall surfaces. The temperature value at the side walls, floor and roof are specified as $312 \mathrm{~K}, 303 \mathrm{~K}$ and $325 \mathrm{~K}$ respectively. These values are based on midday measurements conducted in an actual building during the summer. Since the room analysed in this paper comprises some electrical appliances, humans, their heat generation value is assumed as $25 \mathrm{w} / \mathrm{m}^{2}$. This generated heat is uniformly applied to the floor as a boundary condition. The tetrahedral hybrid $\mathrm{T}$ grid type topological element was used for meshing the flow domain. Approximately 42 cells in the $\mathrm{x}$ direction, 33 cells in the y direction and 42 cells in the $\mathrm{z}$ direction are required for meshing for the mesh node spacing of $0.5 \mathrm{~m}$. This grid structure is independent of the result as verified by repeating the test with a greater number of cells. A 3 dimensional, double-precision, segregated solver is used to solve the governing equations sequentially. Standard k- $\varepsilon$ turbulence model is employed. It is a two equation model in which the solution of two separate transport equation allow the turbulence velocity and length scale to be independently determined. It is a semi empirical model and the derivation of the model equation relies on phenomenological considerations and empiricism. This model is widely used in industrial flow and heat transfer simulation with reasonable accuracy and robustness. In the solution control, second order upwind method was specified. All the cases are iterated up to the 


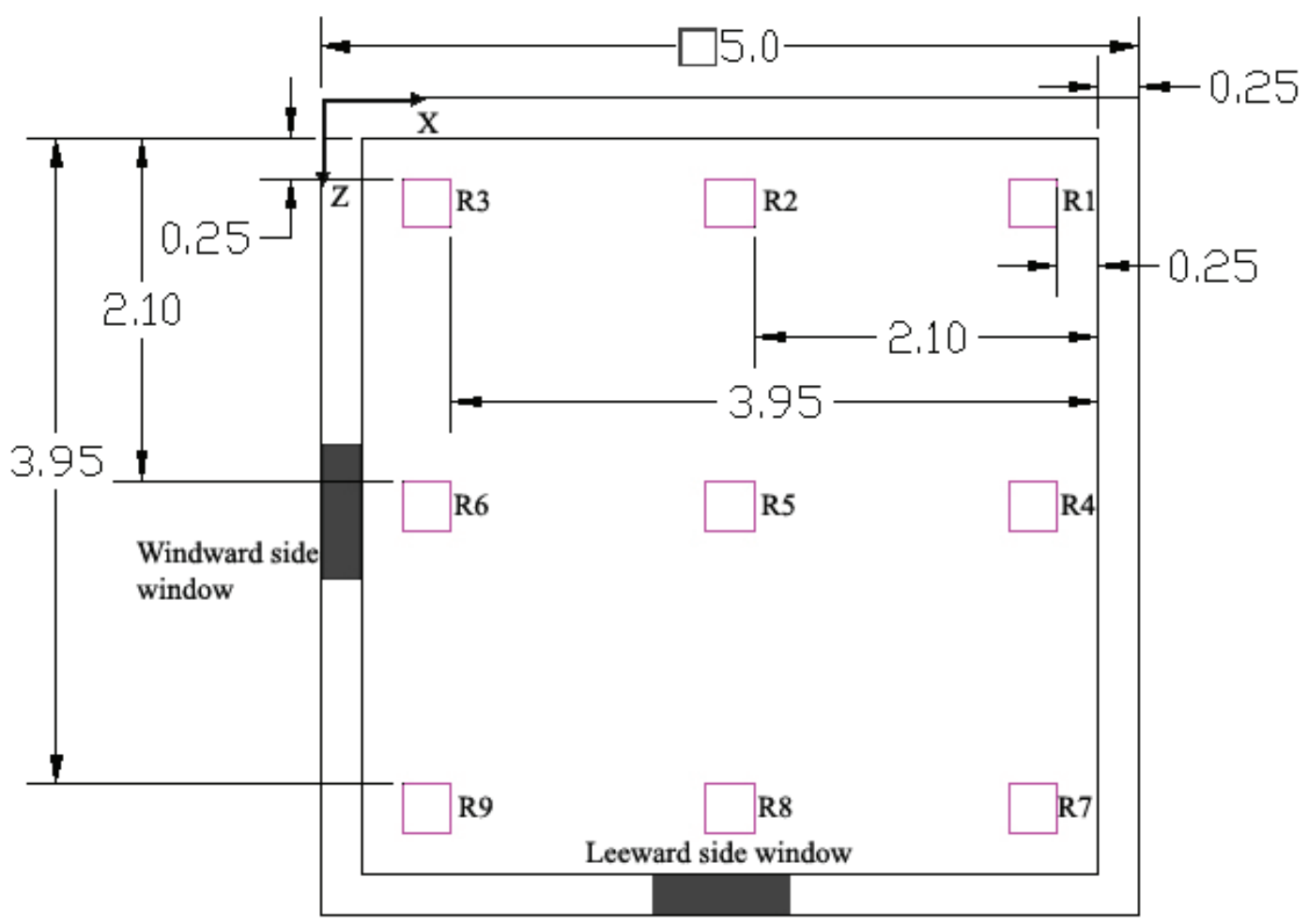

Figure 2. Roof top view-showing the various locations of roof vent.

convergence level of $10^{-6}$. In this work, a low temperature zone of range 306 to $307 \mathrm{~K}$ and low velocity zone of range 0 to $0.1 \mathrm{~m} / \mathrm{s}$ is assumed for the comparison of effectiveness in providing good comfort. After solving the fluid domain to the required convergence level, the mass flow rate of air passing through the window opening at the wind ward sidewall are predicted. The mass flow rate predicted from the CFD simulation is compared with the mass flow rate calculated from the network model given in equation 7.

$$
Q_{\text {network }}=A_{\text {Effective }} \sqrt{(2 \Delta p / \rho)}
$$

$\Delta p$ is calculated from the equation 8 [2].

$$
\Delta p=0.5 \rho V^{2} \mid\left(C_{p n}-C_{p i} \mid\right.
$$

The $C_{p i}$ is determined from the law of conservation and is given in the equation 9 [2].

$$
\mid\left(C_{p n}-\left.C_{p i}\right|^{-0.5}+\mid\left(C_{p(n+1)}-\left.C_{p i}\right|^{-0.5}=0\right.\right.
$$

The pressure coefficient, $C_{p n^{\prime}}$ is the function of wind flow direction.
The predicted mass flow rate from CFD code is compared with the network model and their deviation with the network model was given in table 1 .

The mass flow rate values at the wind ward side opening for all the analyzed cases are having discrepancy in the agreeable level.

\section{Airflow Characteristics by Changing Roof Vent Position}

In the first case a vent of size $0.3 \mathrm{~m} \times 0.3 \mathrm{~m}$ was provided on the roof in addition with window opening of size $(1 \times 1 \mathrm{~m})$ at windward and leeward side walls. The additional roof vent enhances good circulation for indoor air and increases the thermal comfort. The position of roof vent was changed under nine different locations, denoted as R1 to R9 and shown Figure 2.

The temperature plots for all the positions of roof vent are predicted for the xz plane at a height of $1 \mathrm{~m}, 2 \mathrm{~m}$ and $3 \mathrm{~m}$ from the floor surface and are shown in Figure 3. For all the roof vent location, the temperature plot at the plane $y 1$ is similar. However comparatively higher temperature near 
Table 1. Discrepancy of CFD simulation with network model

\begin{tabular}{|c|c|c|c|}
\hline \multirow[t]{2}{*}{ Analyzed cases } & \multicolumn{3}{|c|}{$\begin{array}{c}\text { Mass flow rate of air at wind ward side } \\
\text { window }(\mathrm{kg} / \mathrm{s})\end{array}$} \\
\hline & $\begin{array}{c}\text { Network } \\
\text { model }\end{array}$ & $\begin{array}{l}\text { CFD } \\
\text { prediction }\end{array}$ & Discrepancy \% \\
\hline Roof vent at R1 & 0.774 & 0.7621 & 1.53 \\
\hline Roof vent at R2 & 0.774 & 0.7690 & 0.64 \\
\hline Roof vent at & 0.774 & 0.758 & 2.06 \\
\hline Roof vent at R4 & 0.774 & 0.762 & 1.55 \\
\hline Roof vent at R5 & 0.774 & 0.7618 & 1.57 \\
\hline Roof vent at R6 & 0.774 & 0.7623 & 1.51 \\
\hline Roof vent at R7 & 0.774 & 0.7628 & 1.44 \\
\hline Roof vent at $\mathrm{R} 8$ & 0.774 & 0.7582 & 2.04 \\
\hline Roof vent at R9 & 0.774 & 0.7712 & 0.36 \\
\hline $\begin{array}{l}\text { Cylindrical hole at } \\
\text { windward side wall }\end{array}$ & 0.829 & 0.816 & 1.56 \\
\hline $\begin{array}{l}\text { Convergent hole at } \\
\text { windward side wall }\end{array}$ & 0.829 & 0.8 & 3.49 \\
\hline $\begin{array}{l}\text { Divergent hole at } \\
\text { windward side wall }\end{array}$ & 0.829 & 0.798 & 3.73 \\
\hline $\begin{array}{l}\text { Convergent } \\
\text { divergent hole at } \\
\text { windward side wall }\end{array}$ & 0.78 & 0.772 & 1.02 \\
\hline
\end{tabular}

to the wall W2 was identified for the roof vent case R6, R7, $\mathrm{R} 8$ and $\mathrm{R} 9$. About $0.3 \mathrm{~K}$ increase in temperature was noticed near the wall W2. Among all the roof vent positions, R6 case have more area with high temperature value in the plane $\mathrm{Y} 1$ and case $\mathrm{R} 3$ have more area with low temperature value in the same plane. For the plane Y2, the temperature plots are similar for the cases R1, R4 and R5. Similarly R6, R7, R8 and R9 show similar pattern of temperature at all the regions except the portion nearer to the wall W2. For the plane Y3, case $\mathrm{R} 3$ shows the least temperature in the maximum portions of the plane. Case R6 shows more high temperature zone near to the wall W2. In general, changing the position of the roof vent does not make a drastic affect in the temperature pattern at the planes $\mathrm{Y} 1$ and $\mathrm{Y} 2$. The reason behind this is the roof vent makes a negligible quantity of air to flow towards the roof from the wind ward side. And hence the temperature pattern has a significant change only in the $\mathrm{Y} 3$ plane. Another reason is the size of the roof vent which does not make a drastic change in the temperature pattern. But one phenomenon which is clearly evident from this study is the maximum flow of air takes place near to the wall W1 and W4 since, the wind ward side window and leeward

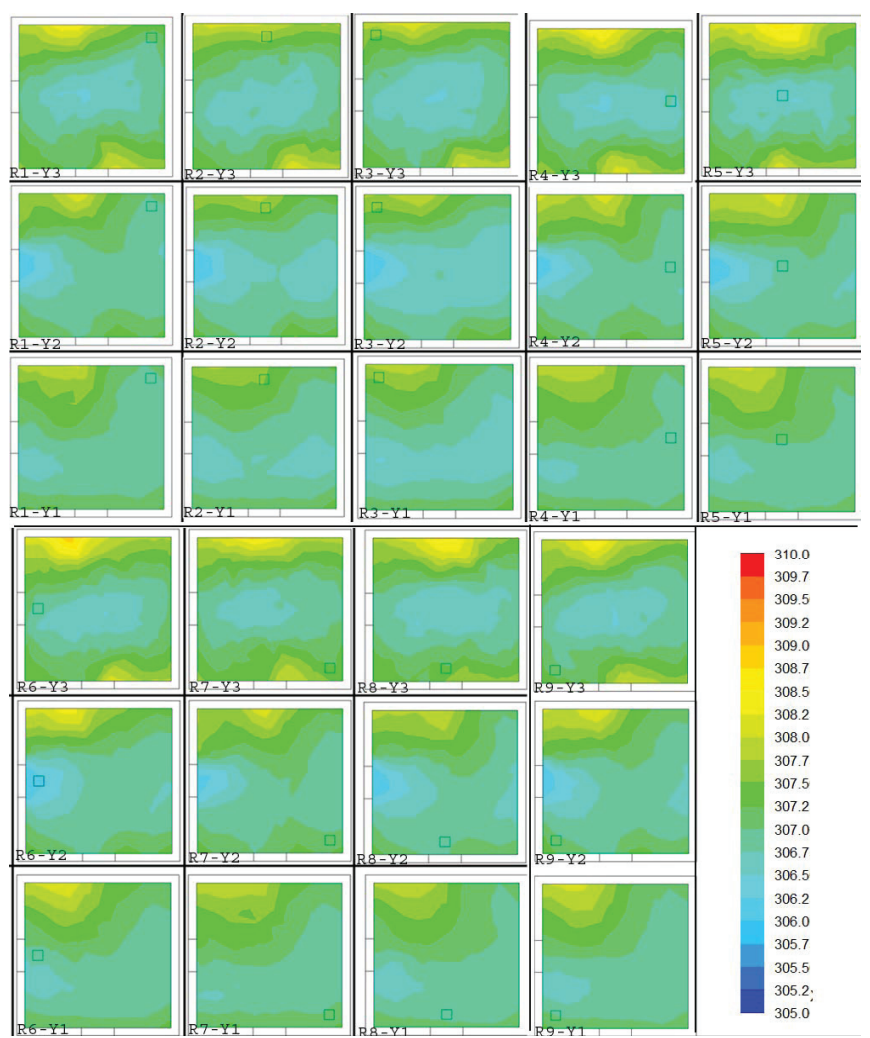

Figure 3. Temperature $(\mathrm{K})$ plot at $\mathrm{XZ}$ plane at a height of 2 $\mathrm{m}$ from ground for various roof vent location.

side window are located in the walls $\mathrm{W} 1$ and $\mathrm{W} 4$ respectively. The effective depth of air travel towards the wall W3 depends on the wind force and hence a very less quantity of air is flowing near the wall W3 for the specified wind velocity. Based on the temperature pattern, certain design aspects in the room are identified for the best location of roof vent. Locating the roof vent nearer to the wall W1 like R6 is not beneficial; however roof vent nearer the wall W2 is more preferable. Among the analysed vent cases, R1, R2 and R3 are nearer to wall W2. Vent location at R2 and R3 are identified as best location and the case $\mathrm{R} 1$ is not preferable since the air is not allowed to travel near to the corner C1.

The velocity plots for the analyzed roof vent cases at the planes y1, y2 and y 3 are shown in Figure 4.

From this figure the velocity plots for the plane $y 1$ is almost similar except the zone nearer to the walls W1, W2, W3 and W4 and rest of the portions are having the air velocity of $0.1 \mathrm{~m} / \mathrm{s}$ to $0.2 \mathrm{~m} / \mathrm{s}$. The plane y2 is also similar for all the roof vent positions. Major portion of the plane y 2 was covered with the air velocity of $0.1 \mathrm{~m} / \mathrm{s}$ to $0.2 \mathrm{~m} / \mathrm{s}$. However a small region in the $\mathrm{y} 2$ plane for the case $\mathrm{R} 3$ is having a slight higher velocity in the range of $0.2 \mathrm{~m} / \mathrm{s}$ to 


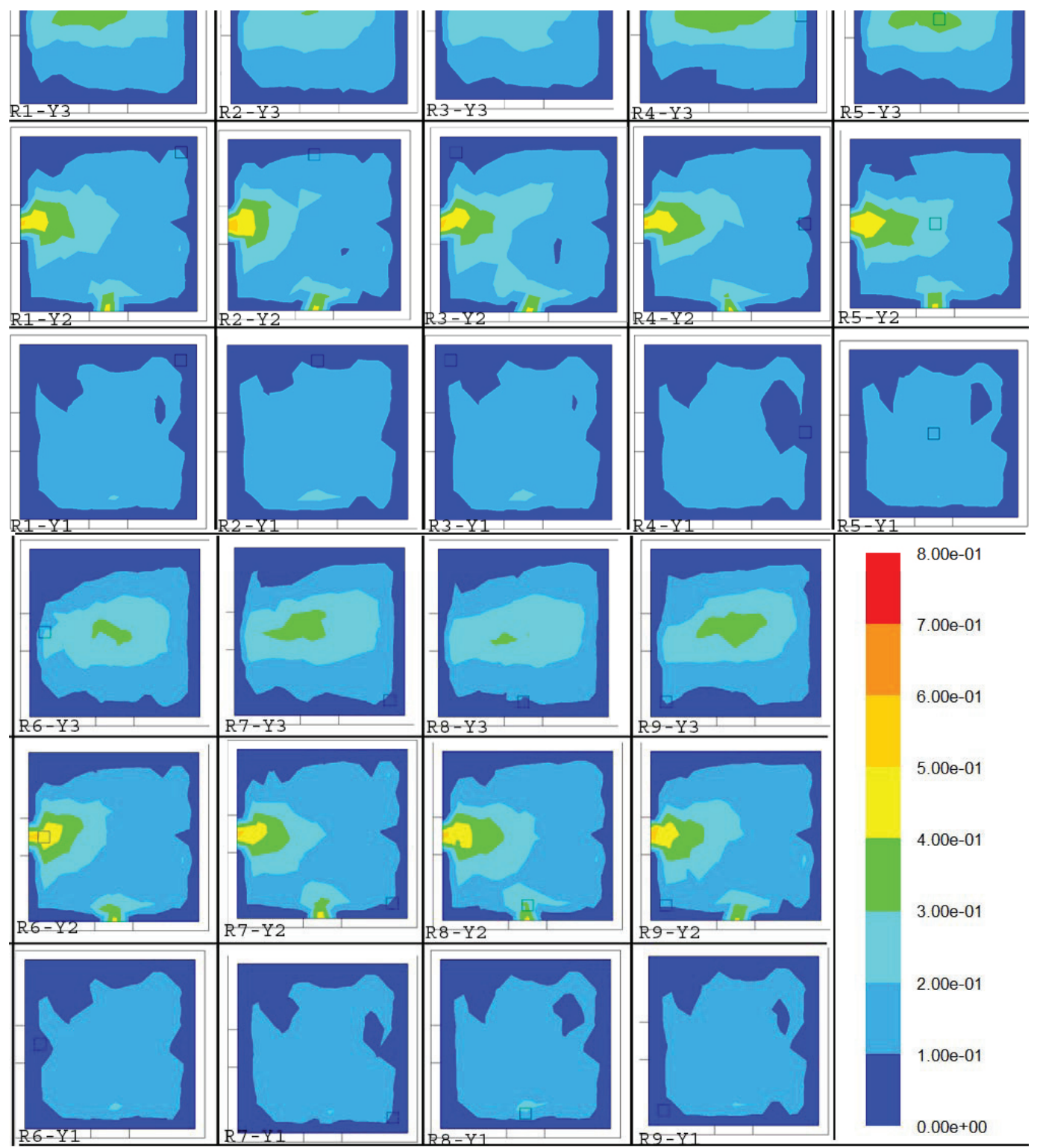

Figure 4. Velocity $(\mathrm{m} / \mathrm{s})$ plot at XZ plane at a height of $2 \mathrm{~m}$ from ground for various roof vent location.

$0.3 \mathrm{~m} / \mathrm{s}$. Plane y3 shows more difference in velocity pattern among the roof vent cases. To identify the best location of roof vent based on the indoor air velocity Figure 7 was shown which consists of area occupied by low velocity zone in the planes y1, y2 and y3.

The above temperature plots and velocity plots are difficult to compare the statistical performance of analyzed roof vent cases and hence another parameter-area occupied low temperature zone and low velocity zone at the planes $\mathrm{y} 1, \mathrm{y} 2$ and $\mathrm{y} 3$ for the positions of roof vent along with room without roof vent are predicted and shown in Figure 5. The low temperature zone is the zone occupied by the temperature in the range of $306 \mathrm{~K}$ to $307 \mathrm{~K}$. Low velocity zone is the portions occupied by the air having the velocity in the range of $0 \mathrm{~m} / \mathrm{s}$ to $0.1 \mathrm{~m} / \mathrm{s}$. From this figure 5 it is evident that roof vent position at the location R3 offers more area of low temperature zone among all the roof vent positions. Case R7 offers the least low temperature zone area. Around $63 \%$ of the room area was kept in low temperature for the roof vent case R3 


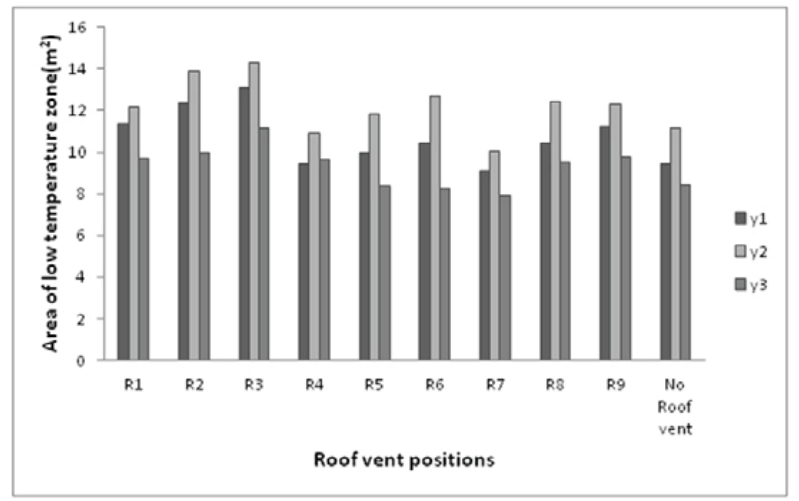

(a)

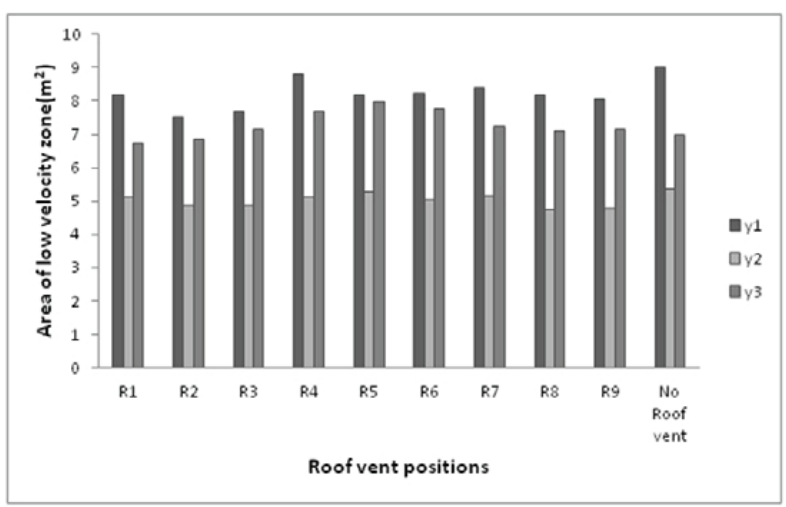

(b)

Figure 5. Area occupied by of low temperature zone and low velocity zone for various roof vent locations.

while the room with out roof vent offers only $47 \%$. Hence room with adjacent windows along with the roof vent nearer to the corner $\mathrm{C} 1$ is the best location for lowering the indoor temperature. Among the 3 planes y1, y2 and $y 3, y 1$ offers the maximum low velocity zone at an average of $40 \%$ of the predicted area. However, the plane y 2 bid only $24 \%$ of the predicted area with low velocity. This is due to the windward side and leeward side window, which encourages the air to travel with an average velocity of $0.3 \mathrm{~m} / \mathrm{s}$. Also the area of low velocity zone in the plane y 2 is almost constant for all the roof vent cases and is having low velocity areas as $4.5 \mathrm{~m}^{2}$ area. The plane $\mathrm{y} 3$ have comparatively more area of low velocity zone with reference to $y 1$ and $y 2$. Among the various positions of roof vents, R2 offers less percentage of low velocity zone of about $31.65 \%$ and next to that R3 offer only $32.4 \%$. In comparison to roof without vent, the difference in the low velocity zone between the plane y1 and $\mathrm{y} 3$ is $2.02 \mathrm{~m}^{2}$ while the same for the case R2 and R3 is 0.64 and 0.52 respectively. This shows that the drastic change in the air velocity value along the y direction is reduced by providing roof vents. Finally the percentage area of low velocity zone for the roof without vent was predicted as 35.11 where as the roof with vent at R2 and R3 is 31.65 and 32.41 respectively. About 3.07\% room interior with low velocity zone was reduced by providing roof with vent at the locations R2 and R3.

\section{Effect of Additional Vent in the Windward Side Window}

In the second case, an additional vent on the windward side was provided along with the roof vent at location R3. This additional vent was located at a height of $0.3 \mathrm{~m}$ from the ground surface. To enhance the flow, the additional vent shape was changed as cylindrical vent (case A), convergent vent (case B), divergent vent (case C) and convergent divergent vent (case $\mathrm{D}$ ) and are shown in Figure 6 . These cases are analyzed under the same methodology and boundary conditions discussed in the section 3 .

The temperature plots at the three different planes y1, y2 $\& y 3$ for the cases A, B, C and D along with the room case with roof vent alone at R3 was shown in Figure 9. For the plane yl, a significant reduction in temperature for the case A was identified in comparison with R3. Also case B, C \& D are having a slight reduction in temperature in comparison with the case of roof vent alone. For the plane y2, a slight variation in the temperature was observed. This negligible variation in temperature is due to the predominant effect of wind force which is common to all the cases. In the plane $\mathrm{y} 3$, both convergent and divergent type vent cases increases the maximum temperature along the wall $\mathrm{W} 3$ and this zone temperature value is in the range of $308.2 \mathrm{~K}$ to $308.5 \mathrm{~K}$, whereas the case A (cylindrical hole) offers comparatively lesser temperature in the range of $308 \mathrm{~K}$ to $308.2 \mathrm{~K}$ near the wall W3.

The velocity plots are also predicted for the same planes and are shown in Figure 8. For the plane y1, the area occupied by the air with velocity 0.2 to $0.3 \mathrm{~m} / \mathrm{s}$ is higher for all the side vent cases and also the zone with air velocity in the range of 0.1 to $0.2 \mathrm{~m} / \mathrm{s}$ increases marginally with reference to the case R3. Similarly, in the plane y2 and y3, the entire additional vent in the windward side window case shows improved air flow pattern. Among the side vent cases, vent with cylindrical shape shows comparatively high air flow velocity.

Again the temperature plots are not much useful to identify the best shape of additional vent on windward 


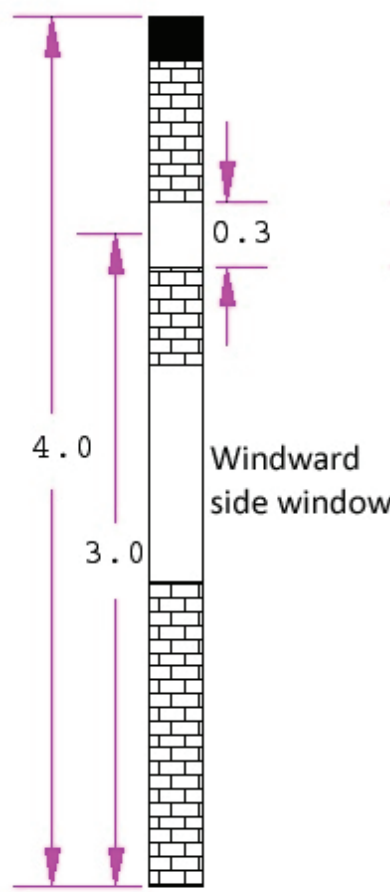

A

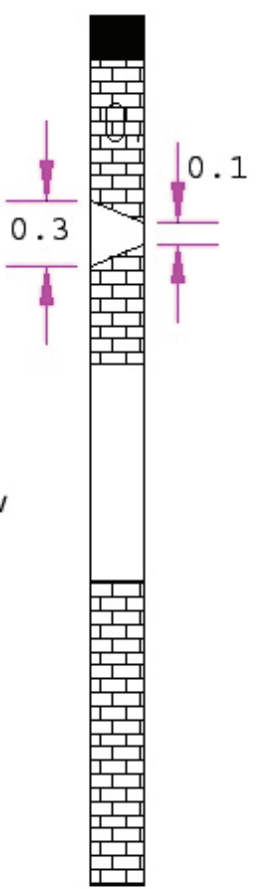

B

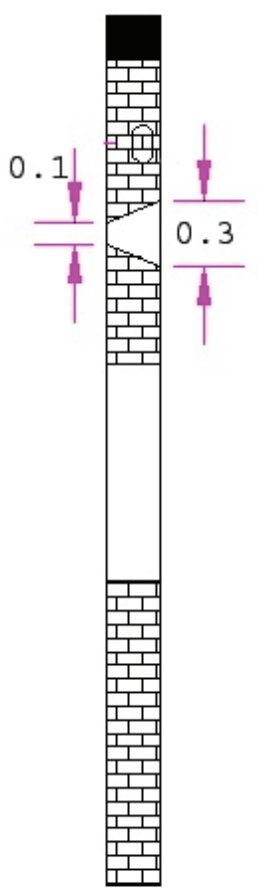

C

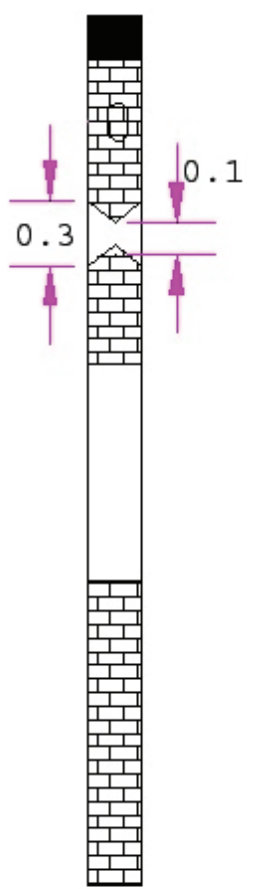

$\mathrm{D}$

Figure 6. Cross sectional view of additional vent at windward side wall: A-Cylindrical, B-Convergent, C-Divergent and D-Convergent divergent.

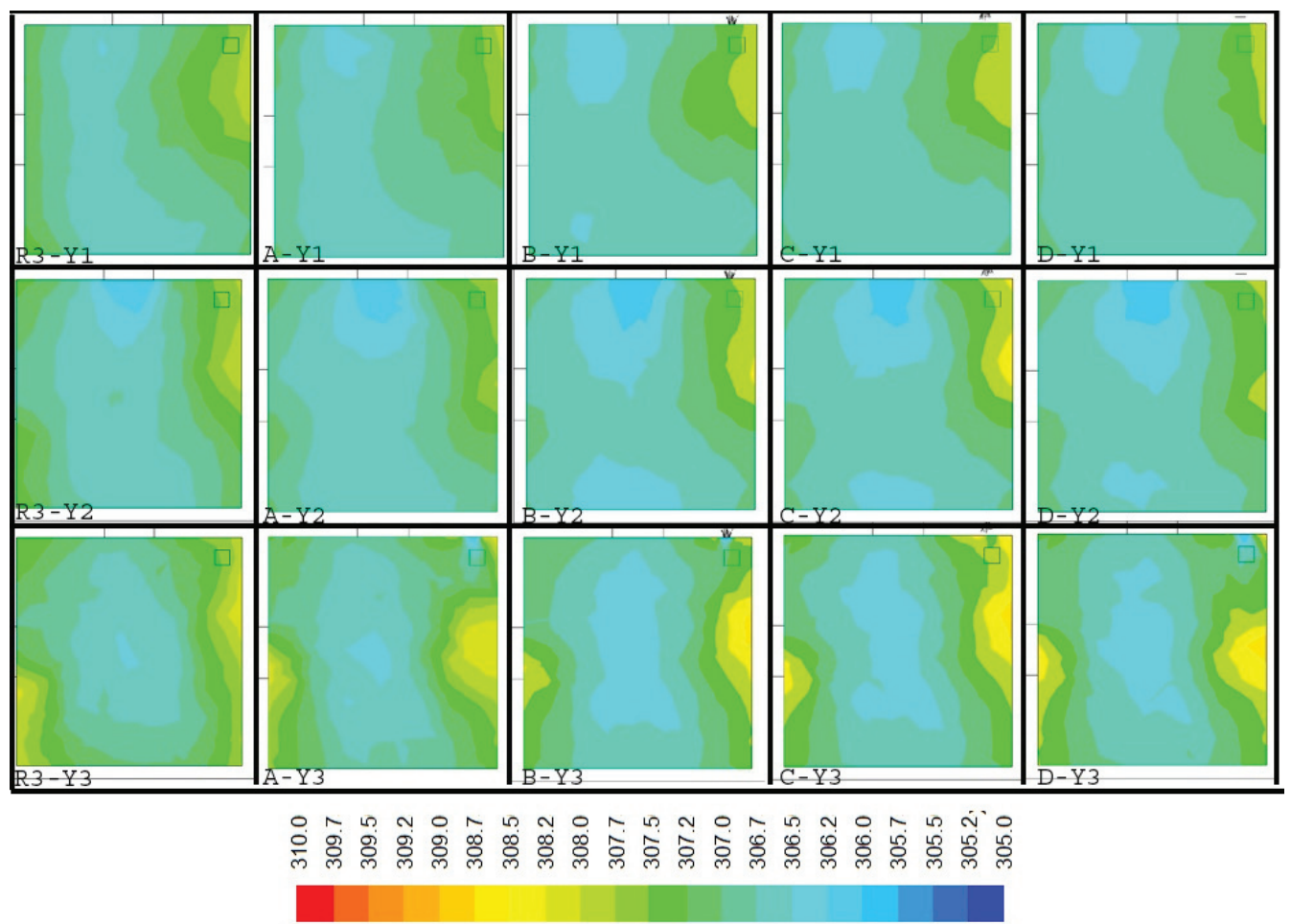

Figure 7. Temperature $(\mathrm{K})$ plot for various shape additional vent at windward side wall. 


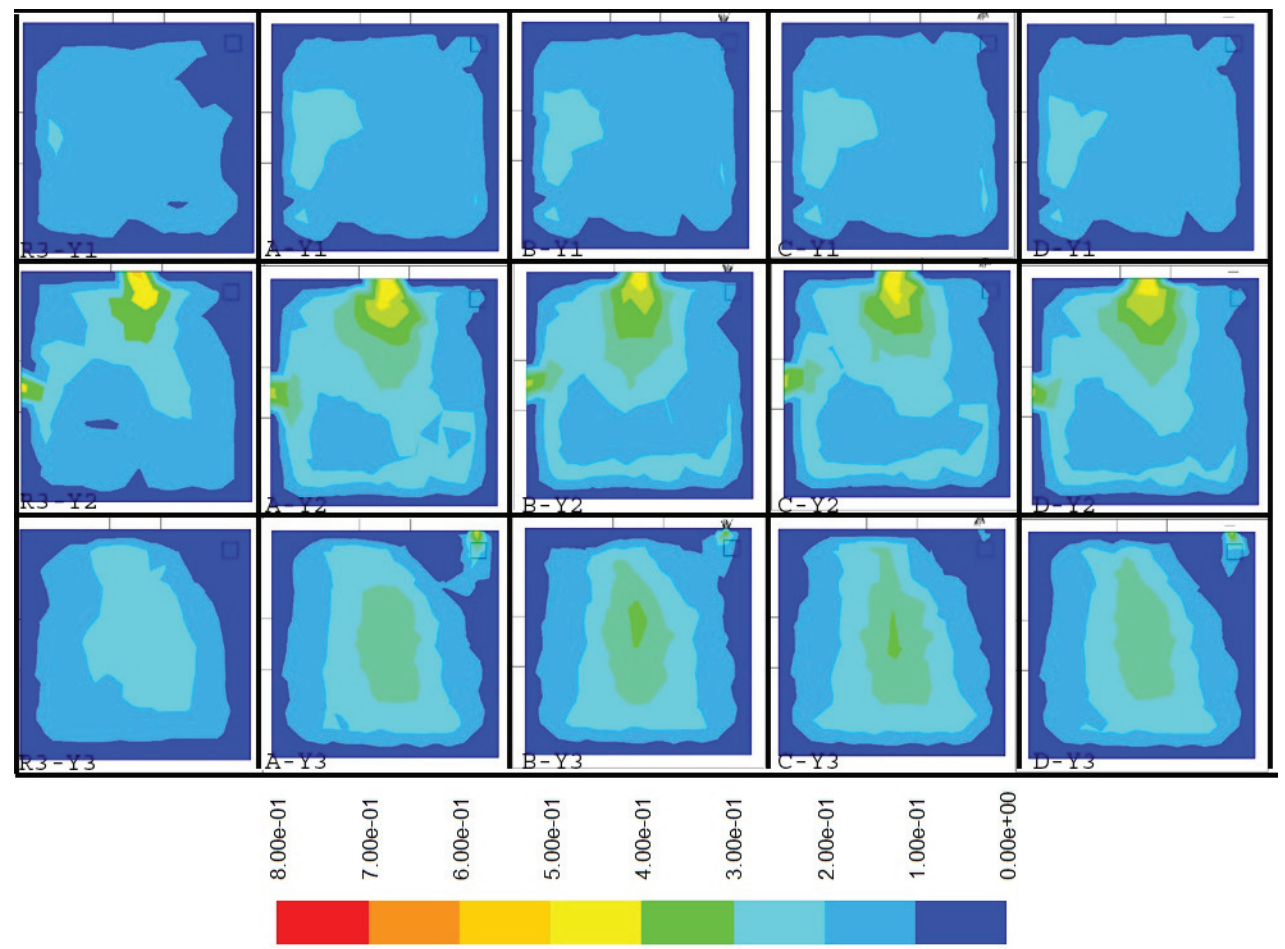

Figure 8. Velocity $(\mathrm{m} / \mathrm{s})$ plot for various shape additional vent at windward side wall.

side window and hence the area occupied by the low temperature zone was predicted at the planes y1, y2 \& y3 and is shown in Figure 9. It is very clear that side vent of cylindrical shape offers $71 \%$ of area with low temperature zone. This value is around $8 \%$ increase in comparison with the room with only roof vent at R3 location. Nozzle type of side vents does not improve the thermal comfort as much and the area occupied by the low temperature zone are also comparatively less.

Figure 9 also shows the area occupied the low velocity zone for the analyzed room cases with additional vent in the windward side window. Case A offers only $29.9 \%$ of area with low velocity zone. While the other nozzle cases B, C and D offers $31.2 \%, 30.9 \%$ and $32.33 \%$ respectively. Plane Y2 was not having a significant change in the low velocity zone among the side vent cases, since the wind force affects the air flow predominantly. In this aspect, case A-additional vent of cylindrical shape was identified as the best one. With all these information, room with roof vent of at R3 location and side vent of cylindrical shape increases the area of low temperature zone by $23.7 \%$ and the reduces the low velocity zone by $5.16 \%$ in comparison with the room having window opening only at the adjacent walls.

\section{Thermal Comfort Index}

Fanger [3] developed a thermal comfort model based on a physical assessment of heat exchange between the human body and the environment. The factors affecting heat exchange from the human body are metabolic rate $M$, work completed $W$, and clothing. Environmental factors include air temperature $T_{a}$, mean radiant temperature $T_{r}$, air velocity $v$, and vapor pressure of air $p_{a}$. A seven point psychological scale was developed to determine the thermal sensation index. This thermal sensation index was called as predicted mean vote (PMV). The PMV value has a range of +3.0 to -3.0 , corresponding with the hot and cold thermal conditions. Fanger's equation for PMV prediction is provided in Eq. (10).

$$
\begin{aligned}
& P M V=\left(0.303 e^{-0.036 M}+0.028\right)\left\{(M-W)-3.05 \times 10^{-3}\right. \\
& {\left[5733-6.99(M-W)-p_{a}\right]-0.42[(M-W)-58.15]-1.7 \times 10^{-5}} \\
& M\left(5867-p_{a}\right)-0.0014 M\left(34-T_{a}\right)-3.96 \times 10^{-8} f_{c l}\left[\left(T_{c l}+273\right)^{4}\right. \\
& \left.\left.-\left(T_{r}+273\right)^{4}\right]-f_{c l} h_{c}\left(T_{c l}-T_{a}\right)\right\}
\end{aligned}
$$




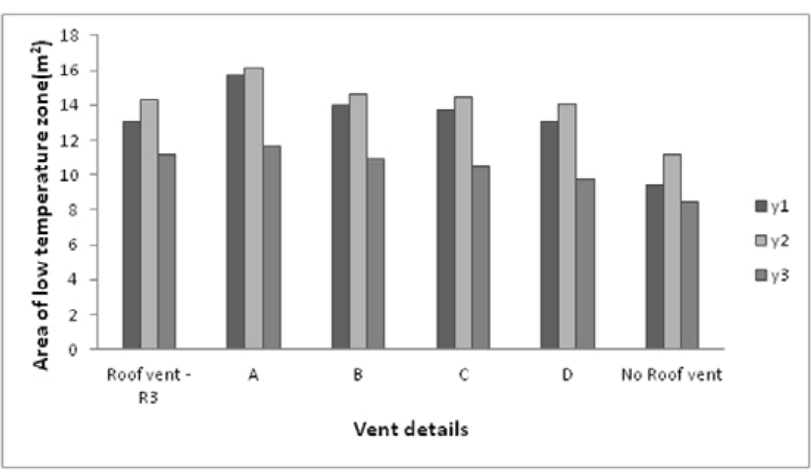

(a)

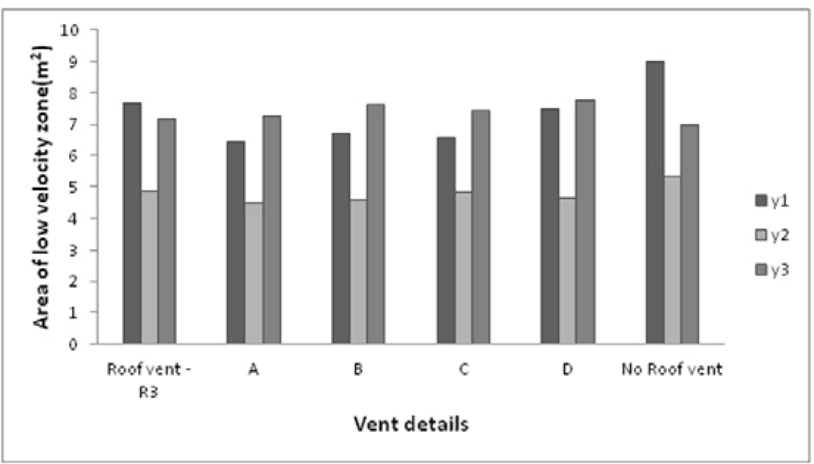

(b)

Figure 9. Area occupied by low temperature zone (K) and low velocity zone for various shape additional vent at windward side wall.

where, $f_{c l}=$ factor of clothing, $T_{c l}=$ clothing temperature, $h_{\mathrm{c}}=$ convective heat transfer coefficient. In this study, the PMV contours at the midplane and parallel to the floor at a height of $2 \mathrm{~m}$ from the floor are predicted and are shown in Figure 10.

The metabolic rate, work completed and thermal resistance of clothing are assumed as $70 \mathrm{~W} / \mathrm{m}^{2}, 30 \mathrm{~W}$, and $0.11\left(\mathrm{~m}^{2} \cdot \mathrm{k}\right) / \mathrm{W}$, respectively. For the room with only windows at the adjacent wall will have the PMV value in the range of 2.24 to 2.40 . The zone nearer to the windward side window will experiences the low value of PMV as 2.24 and 2.26. But major portion of the room is having the PMV value of 2.29 and the PMV value is increasing towards the wall W2 as 2.40. Hence it is identified that portion nearer to wall W2 is affected by high PMV value and this zone is required to cool further. Another portion nearer to wall W3 is also experiencing high PMV value as 2.30. By providing the roof vent in addition to the window openings,

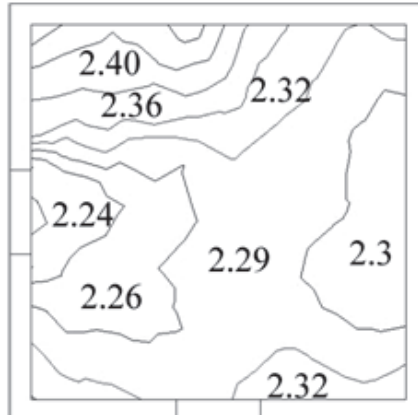

(a)

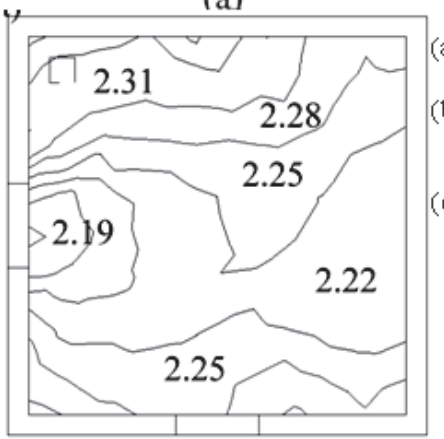

(c)

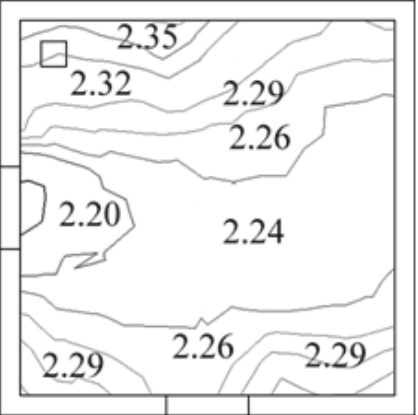

(b)

a) Room with only window openings

(b) Room with window openings and roof vent at $\mathrm{R} 3$

(c) Room with window openings, roof vent at R3 and cylindrical vent at windward side wall
Figure 10. PMV contours at $\mathrm{XZ}$ plane and mid height of the building.

the PMV value is reduced and it is ranging from 2.23 to 2.34. The roof vent stales out the indoor air and their by recirculation of air inside the room was reduced and leads to feel slight comfort. In this case also, the PMV value is increasing towards the wall W2, but the difference in PMV value from center portion of the room to the wall $\mathrm{W} 2$ is slightly reduced in comparison with room with only window openings. This roof vent reduces the average PMV value by 0.05 . In the third case, room with additional roof vent and cylindrical shape vent at windward side, further reduction in the indoor room temperature was identified and hence the PMV value gets decreased. In this case, the $\mathrm{PMV}$ value is ranging from 2.22 to 2.31 . The centre portion of the room is having the PMV value of 2.23 and this value is increasing toward the wall W2 as 2.32. Since the PMV plot is predicted at the mid plane of the room the variations in the PMV value is not much significant between the three cases and this variation will be high enough towards the roof. With all these information, it is best to provide a roof vent at the location R3 along with the cylindrical shape vent in the windward side wall. The size of the additional vent also affects the PMV value but in this paper the effect of providing vent in addition to window openings is only studied. 


\section{Conclusion}

Present paper investigates the change of indoor air flow characteristics by providing the additional vent at roof and windward side wall along with the window openings at the adjacent walls. CFD technique was employed to simulate the air flow and it is compared with network model for validation. Two different analysis were performed namely studying the effect of roof vent location and shape of the side vent in the windward side wall. In the first study the roof vent was located in nine different locations and the CFD simulations were performed. From this study the best location of the roof was identified at R3 location. Providing the roof vent increases the area of low temperature zone by $16 \%$ and reduces area the low velocity zone by $3 \%$. Another important fact was also identified that the zone nearer to wall W2 is the region affected by high temperature and low velocity and hence an additional vent is provided at the windward side wall. The effect of additional vent at the windward side wall along with the roof vent at R3 location was studied by varying its shape as cylindrical, convergent, divergent and convergent divergent. Cylindrical shape vent is identified as the best shape and this type of vent further improves the thermal comfort by increasing the area of low temperature zone and reducing the low velocity zone as $23.7 \%$ and $5.07 \%$ further. Nozzle shaped vents are not improving the thermal comfort since the atmospheric wind velocity is in the range of 0.2 to $1.5 \mathrm{~m} / \mathrm{s}$. Also, the thermal comfort index, predicted mean vote value for the room with window openings alone, with roof vent at $\mathrm{R} 3$ and for room with roof vent at R3 along with a cylindrical side vent was predicted. From this PMV contour, room with roof vent and cylindrical side vent reduces the average PMV value by 0.06 . With all these findings, the best position of vent at roof was identified as R3 and cylindrical shape of side vent at windward side wall is chosen for improved and uniform thermal comfort.

\section{References}

1. Mochida A, Yoshino $\mathrm{H}$ et al. (2005). Methods for controlling airflow in and around a building under cross-ventilation to improve indoor thermal comfort, Journal of Wind Engineering and Industrial Aerodynamics, vol 93(6), 437-449.

2. Asfour O S, and Gadi M B (2007). A comparison between CFD and network models for predicting wind-driven ventilation in buildings, Building and Environment, vol 42(12), 4079-4085.
3. Awbi H B (2003). Ventilation of Buildings, $2^{\text {nd }}$ Edn, Taylor \& Francis, Spon press.

4. Chang W R (2006). Effect of porous hedge on cross ventilation of a residential building, Building and Environment, vol 41(5), 549-556.

5. Chu C R, Chiu Y H et al. (2010). An experimental study of wind-driven cross ventilation in partitioned buildings, Energy and Buildings, vol 42(5), 667-673.

6. Song D, and Kato S (2004). Radiational panel cooling system with continuous natural cross ventilation for hot and humid regions, Energy and Buildings, vol 36(12), 1273-1280.

7. Evalo G, and Popov V (2006). Computational analysis of wind driven natural ventilation in buildings, Energy and Buildings, vol 38(5), 491-501.

8. Favarolo P A, and Manz H (2005). Temperature-driven single-sided ventilation through a large rectangular opening, Building and Environment, vol 40(5), 689- 699.

9. Fisk W J, and Rosenfeld A H (1997). Estimates of improved productivity and health from better indoor environments, Indoor Air, vol 7(3), 158-172.

10. Hoang M L, Verboven P et al. (2000). Analysis of the air flow in a cold store by means of computational fluid dynamics, International Journal of Refrigeration, vol 23(2), 127-140.

11. Huo Y, Haghighat F et al. (2000). A systematic approach to describe the air terminal device in CFD simulation for room air distribution analysis, Building and Environment, vol 35(1), 563-576.

12. Caciolo M, Stabat P et al. (2012). Numerical simulation of single sided ventilation using RANS and LES and comparison with full scale experiments, Building and Environment, vol 50, 202-213.

13. Mendell M J, and Fisk W J (1996). Elevated symptom prevalence associated with ventilation type in office buildings, Epidemiology, vol 7(6), 583-589.

14. Rouaud O, and Havet M (2002). Computation of the airflow in a pilot scale clean room using $\mathrm{k}-\varepsilon$ turbulence models, International Journal of Refrigeration, vol 25(3), 351-361.

15. Ravikumar P, and Prakash D (2009). Analysis of thermal comfort in an office room by varying the dimensions of the windows on adjacent walls using CFD: a case study based on numerical simulation, Building simulation, vol 2(3), 187-196.

16. Stavrakakis G M, Koukou M K et al. (2008). Natural cross-ventilation in buildings: building-scale experiments, numerical simulation and thermal comfort evaluation, Energy and Buildings, vol 40(9), 1666-1681.

17. Jiang Y, and Chen Q (2003). Buoyancy driven single sided natural ventilation in buildings with large openings, International Journal of Heat and Mass Transfer, vol 46(6), 9773-988. 